\title{
Mechanisms underlying the effects of stress on tumorigenesis and metastasis (Review)
}

\author{
ZHAOZHOU ZHANG, YAN WANG and QI LI \\ Department of Medical Oncology and Cancer Institute of Integrative Medicine, Shuguang Hospital, \\ Shanghai University of Traditional Chinese Medicine, Shanghai 201203, P.R. China
}

Received March 16, 2018; Accepted July 18, 2018

DOI: $10.3892 /$ ijo.2018.4570

\begin{abstract}
Stress is one of the fundamental survival mechanisms in nature. Although chronic or long-lasting stress can be detrimental to health, acute or short-term stress can have health benefits. The aim of the present review was to address the complexity and significance of stress in tumorigenesis. The review covers an evaluation of previously used and reported experimental animal models of stress, as well as the effects of stress on the neuroendocrine system, immune function, gut microbiota, and inflammation and multidrug resistance, all of which are closely associated with cancer occurrence, progression and treatment. The review concludes that understanding the efficacy of stress management (prevention and rehabilitation) is crucial to the development of comprehensive and individualized strategies for cancer prevention and treatment.
\end{abstract}

\section{Contents}

1. Introduction

2. Stress and animal models of stress

3. Mechanisms underlying the effects of stress on tumorigenesis and metastasis

4. Conclusion

5. Practical perspectives

\section{Introduction}

Stress is a constellation of events that begins with a stressor, leading to stress perception and subsequently resulting in stress response (1). Stress can impair the balance or homeostatic state of an organism physiologically or psychologically

Correspondence to: Professor Qi Li or Dr Yan Wang, Department of Medical Oncology and Cancer Institute of Integrative Medicine, Shuguang Hospital, Shanghai University of Traditional Chinese Medicine, 528 Zhangheng Road, Shanghai 201203, P.R. China

E-mail: lzwf@hotmail.com

E-mail: wangyan_sg@126.com

Key words: stress, tumorigenesis, metastasis, neuroendocrine system, immune function, gut microbiota when exposed to extrinsic or intrinsic adverse forces (2). It is well known that stress is ubiquitous and unavoidable in life. For certain individuals, stress can serve as a stimulant under certain conditions and as a burden under others. In addition, stress serving as a stimulant in certain individuals may be a burden for others, which indicates that there exists a varying degree of stress susceptibility among individuals $(3,4)$. Stress occurs when an organism perceives a disruption, or a threat of disruption, of homeostasis. Factors that can induce stress include, among others, social circumstances, physical environment, hypoxia, emotional state, pain, glucose deprivation, accidents and chronic anxiety (5). Stress-related symptoms include negative emotions or altered mood and behavior, such as anxiety, irritability, anger, startle response, hostility and depression, which can negatively affect various organs of the human body (6). Studies have preliminarily revealed that differences in the stress experienced by different individuals can be due to genetic and environmental factors $(7,8)$. It is also generally believed that moderate stress, such as routine or regular exercise or physical activity, can enhance the body's immune response and reduce the risk of cancer occurrence, progression and mortality $(9,10)$, while chronic stress can affect a number of physiological functions and lead to several diseases, including cancer (11-13) (Table I). Stressors can result in mood and anxiety disorders, including depression, anxiety and irritability, which may be associated with malignancies $(14,15)$.

In order to elucidate the underlying mechanisms linking stress with tumorigenesis and metastasis, it is necessary to establish effective animal models. At present, the most common animal stress models are those developed for chronic restraint stress, maternal separation, and dietary and environmental stress. Tumor metastasis is a complex process that consists of proliferation/angiogenesis, detachment/invasion, embolism/circulation and evasion of immune system surveillance. The present review attempted to classify and summarize the mechanisms underlying the role of stress in tumorigenesis and cancer progression.

\section{Stress and animal models of stress}

Animal models mimicking the pattern of human diseases serve a key role in understanding the effects of stress on cancer. To study this effect, multiple physiological stress models have been 
utilized to promote fear or anxiety in rodents, including the following: i) Social isolation model, where laboratory rodents, which are highly social creatures, are housed individually in cages for extended periods to elicit loneliness; ii) restraint stress model, in which the animals are immobilized or confined to small spaces; and iii) intimidation-induced stress model, which involves placing rodents into the cage of another animal. When categorized by type, stressors are classified as physical (trauma/injury and exercise/exhaustion), cognitive (anxiety and depression), a combination of physical and cognitive (fire-fighting on a 24-h shift) or chemical (environmental toxins and diet). When categorized by duration, stressors are classified as acute (minutes to hours), and chronic (months to years) $(16,17)$.

At present, the chronic mild stress (CMS) model is one of the most widely used stress models, allowing for a combination of a large variety of stressors with different numbers/lengths of intervals and the measurement of different behaviors as a response to rewards (18). Specifically, the CMS model consists of immobilization, forced swimming, noise, hypothermia, social isolation, resident/intruder aggression, maternal deprivation, stroboscopic illumination, cage titling, and food, water or sleep deprivation (19). Meanwhile, the chronic restraint stress animal model is one of the most common immobilizations, in which the duration of restraint has ranged from 1 to $12 \mathrm{~h}$ daily $(20,21)$. Generally speaking, these stress models are evaluated based on three major criteria: i) Construct validity, where the experimental conditions are replicating causes of human diseases; ii) face validity, where the symptoms observed in diseased animals are consistent with clinical observations; and iii) predictive validity, where the animal responds to the treatment currently used in the clinic (22). However, no studies have systematically evaluated the validity or the efficiency of the CMS model, as researchers have often chosen a particular combination of stressors with timing based on previous practical experience and/or the particular requirements of their experiments (18). Stress can be harmful when it is chronic or long lasting, but a fact that is often overlooked is that a stress response can have salubrious adaptive effects in the short run, and that short-term stress may enhance cellular immunity and increase early resistance to cancer $(23,24)$. The timing or duration of the stress models is an important factor that requires consideration. Therefore, it is essential to distinguish between acute and chronic stress in the following discussion (Fig. 1).

\section{Mechanisms underlying the effects of stress on tumorigenesis and metastasis}

Effects of stress on the neuroendocrine system. In the fastpaced society of today, the pressure on individuals is high, and it often manifests itself in the form of anxiety, tension, insomnia and depression, all of which can lead to chronic stress. The hypothalamic-pituitary-adrenal (HPA) axis and the sympathetic nervous system (SNS) are the two branches of the neuroendocrine system that govern the response to stress $(25,26)$. Corticotrophinreleasing hormone $(\mathrm{CRH})$ and arginine vasopressin (AVP), released from the hypothalamus, can activate the pituitary gland to release adrenocorticotropic hormone (ACTH), encephalin and endorphin (END), and the adrenal cortex to release ACTH-induced glucocorticoid (GC) $(3,27)$. The release of CRH is under excitatory input from the amygdala and inhibitory input from the hippocampus (28). Meanwhile, the secretion of CRH and AVP is characterized by a precise circadian rhythm that can be disrupted by imposed stressors, and a circadian rhythm disorder can have the same detrimental effects as chronic stress $(29,30)$. Stress can also result in increased secretion of catecholamines, including norepinephrine (NE) and epinephrine (E), which can enhance alertness and physiological functions, and elicit the fight-or-flight response (31,32). GC serves an important role in the treatment and chemo-resistance of tumors, and catecholamine can promote tumor growth and metastasis $(33,34)$. Adolescent chronic stress cancause HPAhyporesponsiveness and depression-like behavior (35). Psychosocial stressors in cancer can result in the dysregulation of the HPA axis, and vice versa (36). Restraint stress facilitates cancer angiogenesis and metastasis by releasing $\beta$-END, prolactin, increasing concentrations of circulating catecholamine and GC, and increasing tumor-associated macrophage infiltration into the primary tumor $(37,38)$. Psychological stress may attenuate antiangiogenic therapy, primarily through activating $\beta$-adrenergic signaling to promote tumor angiogenesis (39), and $\beta$-blockers or behavioral therapies can limit skeletal metastasis of breast cancer cells (40). Dopamine (DA) is also a catecholamine hormone, which can stabilize tumor blood vessels to block the effects of chronic stress on tumor vasculature, as the depletion of DA under chronic stress conditions creates a permissive microenvironment for tumor growth $(41,42)$. Notably, studies have revealed that DA acts through five types of DA receptors; DA type-1 receptor overexpression is associated with advanced breast cancer and a poor prognosis (43), but DA type-2 receptor has been found to inhibit tumor growth (44).

Furthermore, since the lymphatic system and the pancreas are innervated by fibers of the SNS and have receptors for SNS neurotransmitters, chronic stress-induced SNS activity can increase pancreatic cancer growth, lymphatic vessel contraction and lymphocyte output into the lymphatic circulation. These processes may affect tumor lymphatic dissemination and cancer progression $(45,46)$. Chronic restraint stress can attenuate the levels and function of p53 proteins, and promote the growth of human xenograft tumors, which is mediated by GC elevation during chronic restraint stress (47). A study has shown that exposure to chronic psychological stress may lead to significant changes in the proteomic profile of tumors (48). It is noteworthy that cytokines are potent activators of the central stress response and have regulatory effects on the HPA axis by forming a feedback loop through which the immune/inflammatory system communicates with the brain (49). The duration and magnitude of stress-induced increases in NE, Epi and GC have significant effects on immune cell redistribution and function (50,51) (Fig. 2). However, several studies have indicated that $\beta$-adrenergic receptor blockers can reverse the effects of chronic stress on cancer progression and abrogate drug resistance, which merits further investigation as a novel strategy for cancer treatment (52-54).

Effects of stress on immune function. Stress exerts pleiotropic effects on the immune system, affecting the innate and adaptive immune responses (55). Stress-induced immune responses can be categorized as immune-protective, immune-pathological and immune-inhibitory. Notably, stress can be categorised as good or bad, based on the duration of 
Table I. Differences between acute stress and chronic stress.

\begin{tabular}{|c|c|c|c|}
\hline Differences & Chronic stress & Acute stress & (Ref.) \\
\hline Duration & Prolonged-term (months to years) & Short-term (minutes to hours) & $(16,17)$ \\
\hline Intensity & Strong/weak intensity stimulation & Strong intensity stimulation & $(1,2,8,9,12)$ \\
\hline Animal models & $\begin{array}{l}\text { Social isolation, chronic mild stress, } \\
\text { intimidation }\end{array}$ & Electric shock, immobilization & $(19,20,21)$ \\
\hline Response system(s) & Mainly activates the HPA axis & $\begin{array}{l}\text { Activates the HPA axis and } \\
\text { the sympathetic neural system }\end{array}$ & $(5,25,26,31,32)$ \\
\hline Origin & Adrenal medulla & Adrenal medulla and sympathetic ganglia & $(5,27,28,45,46)$ \\
\hline Response outcomes & $\begin{array}{l}\text { Elevations in catecholamines, i.e., } \\
\text { epinephrine and norepinephrine }\end{array}$ & $\begin{array}{l}\text { Elevations in catecholamines } \\
\text { and glucocorticoids }\end{array}$ & $(5,25-28)$ \\
\hline Immune response & $\begin{array}{l}\text { Immune suppression/ } \\
\text { immune pathology }\end{array}$ & Immune protection/immune pathology & $(56,57,59-62)$ \\
\hline Possible significance & Detrimental & Beneficial & $(9,10,11,13)$ \\
\hline Tumor & $\begin{array}{l}\text { Tumor development } \\
\text { and progression }\end{array}$ & Inhibits tumor development and progression & $(11-13,24-26)$ \\
\hline
\end{tabular}

HPA, hypothalamic-pituitary-adrenal.

the biological stress response (11). It is well known that acute stress can enhance immune function, whereas chronic stress can suppress it, as well as increasing the susceptibility to cancer (1). Stress can have beneficial and harmful effects, depending on the type of immune response; factors that determine the effects of stress on immune function include duration (acute or chronic), endogenous versus synthetic GCs and time of stressor (at early stages or late stages of the immune response) $(1,56)$ (Fig. 1). It has been reported that chronic stress can affect individual components of the cellular immune system and downregulate the cellular immune response $(57,58)$, which manifests in the form of a significant decrease in body weight and lymphatic organs (spleen, thymus and axillary lymph nodes) and a significant increase in the apoptotic cell count in all lymphatic organs (59). Chronic stress may influence the immune function and promote tumor growth by depressing T-cell-mediated immunity and reducing the lymphocyte count, which may depend on toll-like receptor 9 and $\beta$-arrestin 2 (60,61). Cytotoxic T lymphocytes (CTLs) are capable of secreting cytokines, such as interferon- $\gamma($ IFN- $\gamma$ ), and other effector molecules that serve a role in immune surveillance against tumor cells and the eradication of cancer stem cells (62), but NE and GC can decrease the number of CTLs or impair their function to attenuate their antitumor effect (63). However, a previous study found that psychological stress could augment immune response (64). With regards to the effect on non-specific cellular immunity, previous studies have demonstrated that chronic stress can weaken natural killer (NK) cell function and inhibit their activity, promoting tumor progression (65). Stress can also stimulate macrophages or monocytes to secrete interleukin (IL)-1, IL- 6 and tumor necrosis factor (TNF)- $\alpha$, but reduce the secretion of IL-2, IFN- $\gamma$ and major histocompatibility complex (MHC), which may aid tumor cells to evade immune surveillance $(66,67)$. Tumor associated-macrophages (TAMs) are one of the components of the tumor microenvironment in which stress can increase tumor infiltration by macrophages, and macrophage infiltration can mediate stress-enhanced metastasis in primary breast cancer (68). GC can induce macrophage phenotype changes from M1 to M2 to promote tumor progression (69). Daily restraint stress can also lead to increased monocyte chemoattractant protein-1 (MCP-1) expression and infiltration of cluster of differentiation (CD) $14^{+}$ and $\mathrm{CD}^{+} 8^{+}$cells. In addition, the elevation of peripheral blood monocytes and TAMs has been associated with a worse progression-free survival time in patients with ovarian cancer (70). The matricellular protein thrombospondin-1 response to stress via the cluster of differentiation 47 (CD47) and thrombospondin-1/CD47 signaling pathways serves an important role in tumor angiogenesis (71). The upregulated CD47 protein on the surface of cancer cells can combine with signal regulatory protein- $\alpha$, located on the surface of macrophages, in order to avoid phagocytosis. The expression of $\beta 2$-microglobulin (a component of MHC class I molecules) in cancer cells directly protects them from phagocytosis, which is mediated by the inhibitory receptor leukocyte immunoglobulin-like receptor $\mathrm{B} 1$, whose expression is upregulated on the surface of macrophages (72). Dendritic cells (DCs) are specialized antigen-presenting cells that have a direct cytotoxic effect on tumor cells (73), but restraint stress compromises the suppressor function of regulatory T cells (Tregs) and alters DCs to contribute to intestinal inflammation (74). A short-term, stress-induced increase in IFN- $\gamma$, macrophage inflammatory protein- $3 \alpha$, TNF- $\alpha$, MCP-1, IL-1 $\alpha$, IL-1 $\beta$ and IL- 6 can enhance the immunization phase of cell-mediated immunity $(75,76)$. Nevertheless, chronic stress can lead to a reduction in the number of cytokines, including IFN- $\gamma$, IL-2 and IL-12, due to the inhibitory effect of GC, NE and $\mathrm{E}$, which have an important antitumor function $(77,78)$. Chronic stress-induced neuroendocrine changes have been found to suppress the immune response, including NK cell cytotoxicity, phagocytosis, inflammatory cytokine production and cytotoxic T-cell activity, compromising the most important effectors of the immune response against tumors (66). It is 


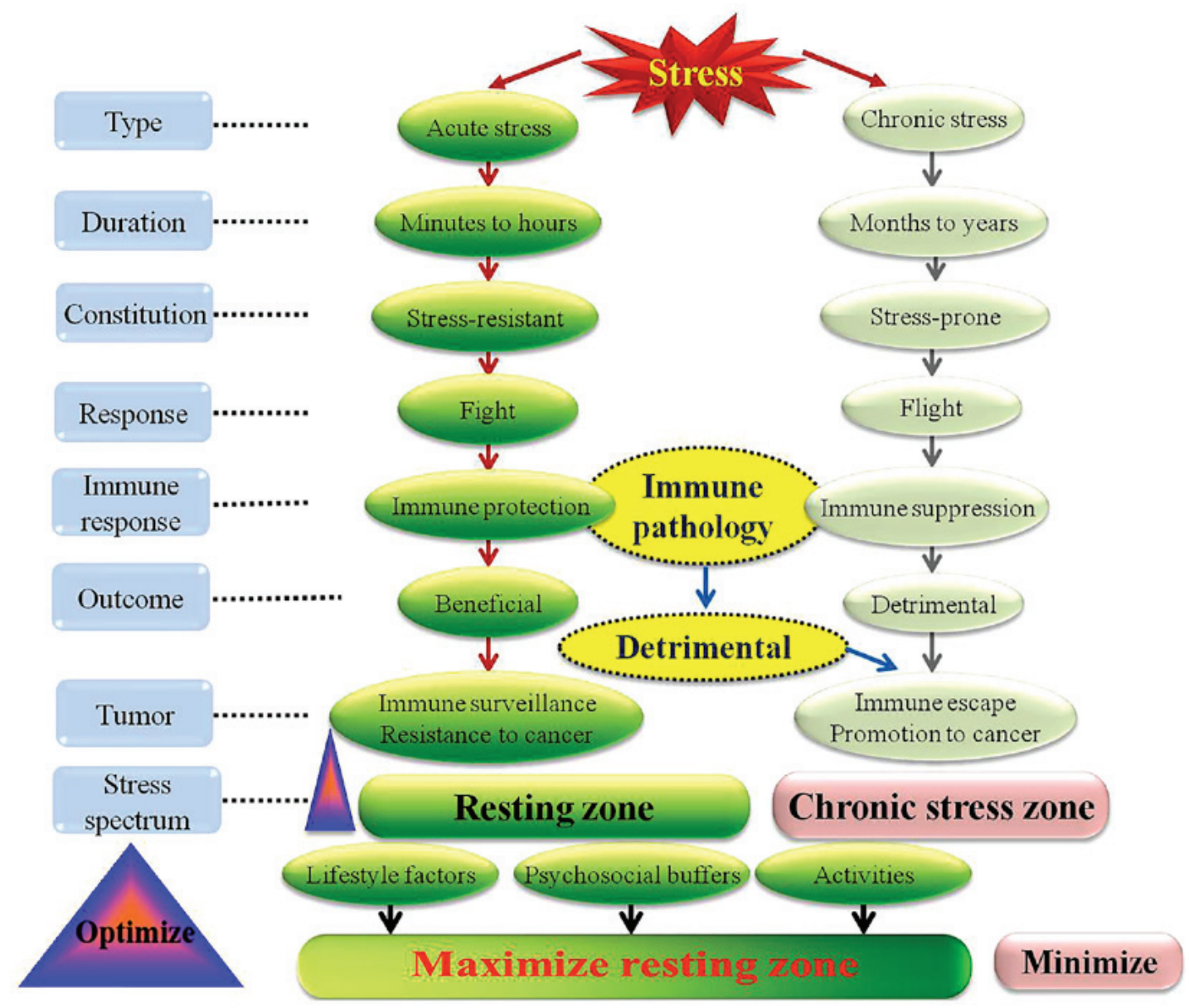

Figure 1. Types of stress and their effects on immune function. Stress can be categorized as either chronic or acute, based on its effects on the body and its duration. Certain individuals are more prone to stress, while others more resistant; this is due to constitution-associated differences among individuals. The fight-or-flight stress response is one of the fundamental defense mechanisms in nature that enables the body to survive. Acute stress can serve an important role in the 'fight' response by exerting immune protection functions, which can prove beneficial to the body and strengthen immune surveillance and resistance to cancer. Chronic stress, on the other hand, can serve an important role in the 'fight' response, which is detrimental to the body and may lead to immune suppression or immune escape, as well as promote cancer. It is worth noting that acute stress may also lead to immunopathology when it is experienced during self/innocuous antigen/allergen exposure, which can result in the increase of pro-inflammatory cytokines and is harmful to the body. According to the aforementioned model, there exists a resting zone between chronic (harmful) and acute (beneficial) stress, and the extent and efficiency with which an organism returns to its resting zone following stress depends on its resilience. Certain factors, such as lifestyle, psychosocial buffers and activities, can maximize the resting zone by optimizing beneficial stress and minimizing harmful stress, which enables the body to stay on the positive side of the stress spectrum.

worth highlighting that, as the largest organ and the body's first line of defence, cutaneous cell-mediated immunity serves an important role in the elimination of immune-responsive tumors such as squamous cell carcinoma (24). Short-term stress not only enhances primary cutaneous immune responses, but also augments secondary or recall responses in the skin (79). In addition, the lymphatic system serves an important role in immune function, while also contributing to tumor cell invasion and metastasis. Studies have found that chronic stress can promote tumor cell dissemination by remodeling the lymph vasculature $(80,81)$.

Effects of stress on the gut microbiota. The gut microbiota serves an important role in maintaining gut homeostasis (82). The most common bacterial phyla in the gut include the Firmicutes, Bacteroidetes, Actinobacteria and Proteobacteria, and the composition of the gut microbiota is highly sensitive to chronic stress $(83,84)$. Furthermore, stress during the perinatal period can markedly influence the microbiota, leading to long-lasting immunological aberrations (85). It has been demonstrated that microbiota dysbiosis is closely associated with the occurrence, development and treatment of cancer $(86,87)$. Certain bioactive substances of the microbiota metabolite production have also been found to be involved in carcinogenesis (88). The influence of the gut microbiota on tumorigenesis and development is mainly through several methods that include direct contact with the tumor (89), affecting the tumor cells by regulating body metabolism indirectly $(90,91)$ and promoting tumor progression by regulating the immune system $(92,93)$. Studies performed on a restraint stress mouse model suggested that commensal microbiota can affect the postnatal development of the HPA stress response (94), and that gut dysbiosis is associated with brain dysfunction and stress-related behavior, including anxiety and depression $(95,96)$. It was shown that the absence of the gut microbiota enhanced anxiety-like behavior and neuroendocrine response to acute stress in rats (97). Chronic stress can not only cause an imbalance in and disorders of the gut microbiota, but also behavioral, cognitive and biochemical aberrations, which may be involved in the microbiota-gutbrain axis. A study revealed that Lactobacillus helveticus NS8 




Figure 2. Systemic effects of stress on the neuroendocrine system. The HPA axis and the SNS are the two key branches of the neuroendocrine system that govern the response of an organism to stress. In response to stress, the paraventricular nucleus of the hypothalamus secretes CRH and AVP, which cause the pituitary gland to secrete ACTH. Meanwhile, the CRH/AVP neurons and central catecholaminergic neurons of the locus coeruleus/NE system are reciprocally innervated and activated. The secretion of CRH and AVP is characterized by a precise circadian rhythm. Subsequently, ACTH stimulates the adrenal cortex to release GC and cortisol. In addition, the HPA axis is controlled by feedback loops that tend to normalize the time-integrated secretion of cortisol. The SNS originates in the brain stem, with the sympathetic nerves located between the intermediolateral column of the T1 and L3 vertebrae. From there, cells synapse with post-synaptic ganglia located in the sympathetic trunk or in splanchnic ganglia throughout the body, and ultimately release NE. Under the condition of stress, particularly chronic stress, NE can promote tumor growth and metastasis. In the image, solid lines indicate stimulation and dashed lines indicate inhibition. HPA, hypothalamic-pituitary-adrenal; SNS, sympathetic nervous system; CRH, corticotrophin-releasing hormone; CRF, corticotrophin releasing factor; AVP, arginine vasopressin; ACTH, adrenocorticotropic hormone; IL-6, interleukin-6; NE, norepinephrine; Epi, epinephrine; GC, glucocorticoid; DA, dopamine.

can improve chronic restraint stress-induced behavioral and cognitive dysfunction (98). Rifaximin can alter the bacterial population in the ileum of rats and lead to a relative abundance of Lactobacillus, which can prevent intestinal abnormalities and visceral hyperalgesia in response to chronic psychological stress (99). A study showed that probiotic treatment attenuated the HPA response to acute stress (100). Notably, a recent study demonstrated that dietary bioactive compounds and probiotics could reduce the risk of colon cancer by shaping functional gut microbiota (101). In addition, resident gut bacteria can affect patient response to cancer immunotherapy, and maintaining a healthy gut flora could assist patients in their fight against cancer (102). Based on the aforementioned literature, we tentatively conclude that there may be an association of mutual causality between tumorigenesis and gut microbiota imbalance.

Effects of stress on inflammation. Approximately 25\% of all cancer types are associated with chronic inflammations of broad origin (103). Just as stress can be divided into acute and chronic according to its beneficial or detrimental effects on the body, so can inflammation. It has been shown that chronic inflammatory processes affect all stages of tumor development, as well as the efficacy of therapy, particularly in gastric, hepatic and colorectal cancer $(104,105)$. There are two major signaling pathways underlying cancer-related inflammation: The transcription factor nuclear factor $-\kappa \mathrm{B}(\mathrm{NF}-\kappa \mathrm{B})$ and the signal transducer and activator of transcription 3 signaling pathways, which can be activated by the majority of cancer risk factors, including stress, diet, infectious agents and environmental pollutants (106). Studies have also revealed that inflammatory cells can be recruited by stress to tumor sites, increasing the formation of blood vessels (107). Meanwhile, stress-inducible inflammatory factors and genes, including IL-6, IL-8 and vascular endothelial growth factor, are increased in the circulation following stressor exposure. Stress can lead to metastatic invasion and metabolic syndrome by the activation of the HPA axis and SNS, respectively, which are characterized by an increased production of IL- 6 , TNF- $\alpha$, llasminogen activator inhibitor-1 and metalloproteinase-2 and -9 (108). Reciprocally, adipose-derived IL-6 may further stimulate the HPA axis, forming a deleterious vicious cycle (109). Chronic psychological stress can induce vascular inflammation via the TNF- $\alpha$ 
and p38/c-Jun N-terminal kinase pathways and increase the expression of inflammatory molecules, including mRNA and proteins such as TNF- $\alpha$, C-reactive protein, MCP-1, macrophage migration inhibitory factor and intercellular adhesion molecule-1 (110). Psychological stress-derived prolactin has been shown not only to induce IL-6 and IL-23 production by DCs, the former of which serve a critical role in altering the phenotypes of Tregs, but also to alter Treg properties, leading to intestinal inflammation (75). Chronic restraint stress has been shown to result in a marked decrease in CD4 T cell numbers and intracellular IFN- $\gamma$ expression, while increasing IL-4 production. It was also found that, in chronically stressed mice, treatment with 4-methylhistamine (4-MeH) agonist was able to restore the immune response, particularly via the production of Th1 cytokines. Stimulation of the histamine 4 receptor with 4-MeH modulates the effects of chronic stress on the Th1/Th2 cytokine balance (111). The sympathetic and neuroendocrine responses to psychosocial stress have been shown to have a significant impact on cancer, partly through the regulation of inflammatory mediators (112). Psychological stress increases extracellular adenosine triphosphate (ATP), IL-1 $\beta$ and TNF- $\alpha$ in the hippocampus, and activates the inflammasomes via the release of ATP and the stimulation of the purinergic type $2 \mathrm{X} 7$ receptor (16). Inflammasomes are multiprotein complexes that operate as platforms for the activation of caspase- 1 and can be categorized based on their main constituent as either NLR family pyrin domain containing 1 (NLRP1), NLRP3, NLR family CARD domain containing 4, NLRP6 or absent in melanoma 2. The activation of inflammasomes can lead to the conversion of inactive inflammation mediators to active ones (IL-1 $\beta$ and IL-18), and, subsequently, the active inflammation mediators are secreted to the cell exterior to modulate cell function in an autocrine or paracrine manner. This process may mechanistically explain the link between inflammasome activation and tumorigenesis, angiogenesis or metastasis $(113,114)$. Furthermore, the external IL-1 $\beta$ can initiate self-reinforcing feedback loops to further perpetuate its existence through the IL-1R-MyD88-NF- $\kappa$ B pathway by inflammasome activators (115). Based on the aforementioned findings, the inhibition of inflammasomes or neutralization of their products can have profound effects on carcinogenesis and tumor progression. The stress hormones NE and Epi can enhance IL-8 expression and thereby mediate the effects of stress on the growth and metastasis of ovarian cancer (116). IL-8 gene silencing with liposomal small interfering RNA incorporated in 1,2-dioleoylsn-glycero-3-phosphocholine has been shown to decrease tumor growth and angiogenesis in ovarian cancer. In addition, the increase of pro-inflammatory cytokines has been associated with irritability, insomnia and fatigue, which, in turn, are associated with cancer (117) (Fig. 3).

Effects of stress on chemo-resistance (multidrug resistance). At present, chemotherapy is one of the main treatment strategies for malignant tumors. However, a number of chemotherapeutic approaches fail due to intrinsic or acquired drug resistance, particularly multidrug resistance. Multiple studies have focused on the mechanisms underlying multidrug resistance in cancer, including DNA damage repair (118) and abnormalities in the expression and function of transporters of the ATP-binding cassette superfamily. P-glycoprotein is the member of this mechanism that has been most frequently reported in association with tumor drug resistance, cancer stem cell, epithelial-mesenchymal transitions and hypoxia $(119,120)$. A study on mice showed that psychological stress reduced the antitumor effects of chemotherapeutic drugs and induced chemo-resistance in breast cancer by upregulating multidrug resistance protein 1 via adrenergic stimulation (121). Stress hormones induced by restraint stress, including cortisol and epinephrine, can decrease the efficacy of paclitaxel in triplenegative breast cancer through the induction of DNA damage and ATR serine/threonine kinase and p21 expression (122). Adrenaline can induce chemo-resistance in HT-29 colon adenocarcinoma cells by upregulating the ATP binding cassette subfamily $\mathrm{B}$ member 1 gene expression via $\alpha 2$-adrenergic receptors (123), as well as cisplatin resistance through the activation of the $\mathrm{NF}-\kappa \mathrm{B}$ pathway and subsequent induction of miR-155 (124). One study showed that miR-155 is responsible for the drug resistance in breast cancer cells, by targeting forkhead box O3 (125). Meanwhile, injections of epinephrine or immobilization stress can counteract the antitumor effects of phosphatidylinositol-4,5-bisphosphate 3-kinase inhibitors on prostate cancer xenografts in mice (126). A dynamic network model of apoptosis regulation in prostate cancer indicated that psychological stress could trigger a synergism pattern switch in drug combination therapy (127). However, it is important to note that chemotherapy itself may generate or deteriorate psychological stress, which is known to be accompanied by chronic elevation of plasma catecholamine, conversely leading to chemo-resistance (121). Psychological stress has been found to attenuate the anti-angiogenic efficacy of sunitinib through the activation of $\beta$-adrenergic signaling and the promotion of tumor angiogenesis, which, however, can be improved by the use of $\beta$-blockers (39). Stress hormones have also been shown to promote resistance to epidermal growth factor receptor (EGFR) inhibitor in non-small cell lung cancer, which can be abrogated by combinations of $\beta$-blockers and EGFR tyrosine kinase inhibitors (53). Furthermore, certain gut microbiota, such as Escherichia coli strains, can decrease the efficacy of chemotherapeutic agent gemcitabine by metabolizing and deactivating the active form of the drug (128).

\section{Conclusion}

Stress is one of the fundamental survival mechanisms in nature; it begins with a stressor, leading to stress perception and subsequently resulting in a stress response. Stress can be divided into acute and chronic, mainly according to its respective salubrious or detrimental effects on the health of an individual. Several studies have demonstrated that stress, particularly chronic stress, serves an important role in tumorigenesis and metastasis. Relevant and effective animal models are essential for the study of the effects of stress on cancer and the underlying mechanisms. The induction of CMS or chronic restraint stress has been widely used for the development of experimental models. The stress-induced persistent activation of the HPA axis and SNS has been shown to result in a cascade reaction leading to cross-talk among the neuroendocrine system, the immune system, gut microbiota and inflammation. Further elucidation of the influence of the interactions among these factors in mediating stress-associated effects on tumorigenesis and metastasis is imperative. Novel approaches 


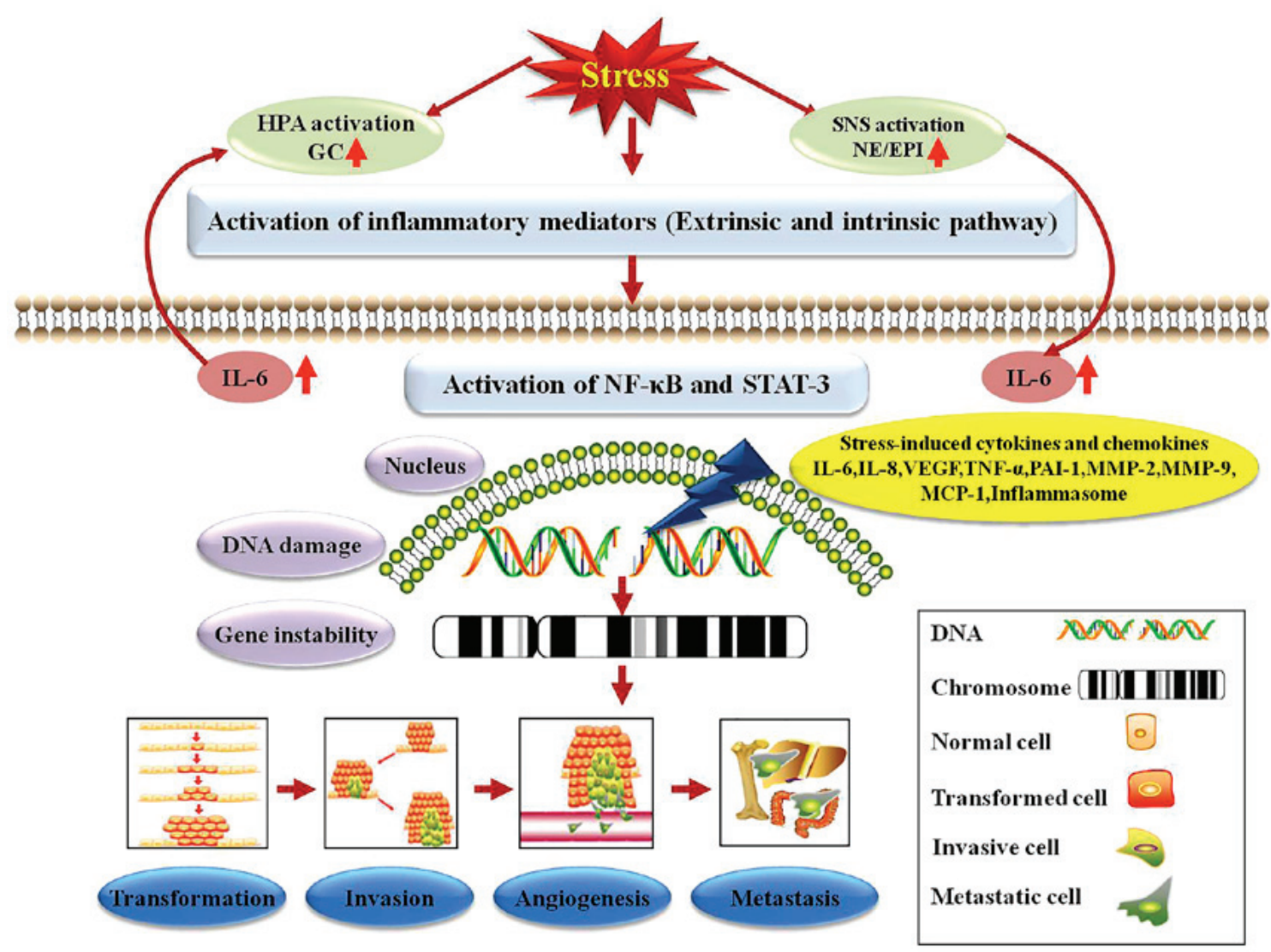

Figure 3. Effects of stress-induced inflammation on tumorigenesis, invasion, angiogenesis and metastasis. Stress, particularly chronic stress, can not only lead to the activation of the HPA axis and SNS, but also activate inflammatory mediators in extrinsic and intrinsic pathways. The transcription factors NF- $\kappa \mathrm{B}$ and STAT3 are the two major pathways linking cancer to inflammation, which can be activated by the majority of cancer risk factors, including stress, diet, infectious agents and environmental pollutants. Stress-induced cytokines and chemokines, including IL-8, IL-8, VEGF, MMP-2 and inflammasomes, have a damaging effect on DNA and can result in gene instability and mutations closely associated with cell transformation, invasion, angiogenesis and metastasis. Furthermore, there exists a vicious circle between the activation of the SNS and the HPA axis, and the secretion of IL-6. Specifically, the activation of SNS can increase the release of IL-6, while IL-6 can trigger the activation of the HPA axis and promote the release of CRH, ACTH and cortisol. HPA,

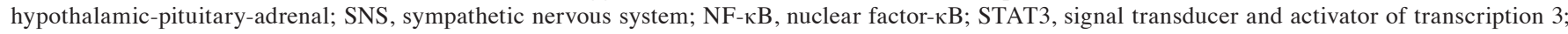
IL, interleukin; VEGF, vascular endothelial growth factor; MMP, metalloproteinase; $\mathrm{CRH}$, corticotrophin-releasing hormone; ACTH, adrenocorticotropic hormone; NE, norepinephrine; Epi, epinephrine; GC, glucocorticoid; IL, interleukin; TNF- $\alpha$, tumor necrosis factor- $\alpha$; MMP, matrix metalloproteinase; MCP-1, monocyte chemoattractant protein-1.

to the prevention and blockage of the harmful effects of stress on tumorigenesis and metastasis are required.

\section{Practical perspectives}

Stress and stress-associated disorders have become prevalent in modern societies due to the fast-paced nature of contemporary lifestyles. Due to their prevalence, such disorders are often concealed, which has detrimental effects to health. Studies have demonstrated that exposure to stress during critical periods in human development is sufficient for it to have severe, long-term consequences $(35,129)$. In addition, chronic stress may lead to epigenetic heritable modifications, suggesting a possible propagation across generations (55). It is noteworthy that stress may exist universally during the diagnosis and subsequent treatment process in patients with cancer (130). On a positive note, it has been shown that effective intervention in cancer patients presenting with stress can improve their immune function and physical activity, and social support can modulate cancer-related pathways and improve the levels of certain biomarkers associated with a better prognosis and longer survival (131). Studies have also revealed that disturbances in mood, anxiety and irritability may precede the appearance of a medical disorder, and that stress-prone personalities or unfavorable coping mechanisms and negative emotional responses are associated with a higher incidence, poorer survival and higher mortality rates in patients with cancer (132). Dhabhar (11) proposed the stress spectrum model and concept, so as to reconcile the potentially beneficial effect of stress with the harmful; according to the stress spectrum model, one can keep fit by minimizing chronic stress, maximizing the resting zone of low/no stress and optimizing the acute stress response.

In the research findings discussed within the present review, it was demonstrated that effective stress prevention and management are plausible and imperative, and that the primary, secondary and tertiary prevention strategies should receive adequate recognition. In particular, moderate exercise, a healthy diet, high-quality sleep and emotional management are key aspects that can be improved in the lives of patients with stress-induced cancer, so that they benefit from them. Regular exercise can assist in keeping the short-term stress response well-oiled, finely-tuned and ready for fight-or-flight (11), as well as improving the physical and emotional well-being of 
an individual. Furthermore, regular exercise has also been shown to reduce the risk for breast cancer recurrence (133). The type, intensity, duration and frequency of exercise should be tailored to the constitution an individual. A number of traditional methods of exercise, including five-animal boxing, eight-section brocade, changing tendon exercise, meditation and yoga, may contribute to successful stress management.

The present review found that diet and gut microbiota play an important role in tumorigenesis and metastasis. Therefore, closer attention should be paid to dietary strategies, and particularly the maintenance of healthy-eating habits. Furthermore, developing effective microbial agents is necessary and promising with regard to the reduction of cancer risks. An association has been identified between lack of sleep or sleep disturbances such as insomnia, fatigue, obstructive sleep apnea and restless legs syndrome, and depression or anxiety (134). The latter are also common among cancer patients, and often comprise the symptoms that lead to the diagnosis of certain types of cancer (135). In addition, circadian cortisol rhythm disruptions serve as an important indicator and/or mediator of the deleterious effects of chronic stress (1). In view of this, future studies are warranted to better understand the mechanisms underlying the effects of stress on tumorigenesis and metastasis.

\section{Acknowledgements}

The authors would like to thank Professor Junfeng Zhang (Duke University, Durham, NC, USA) for the revision of the original manuscript.

\section{Funding}

The present review was supported by the National Natural Science Foundation of China (grant nos. 81573764 and 81774095), the Program for Outstanding Medical Academic Leader, Shanghai Academic/Technology Research Leader (grant no. 16XD1403600), the Shanghai Rising-Star Program (grant no. 16QA1403700) and the Municipal Human Resources Development Program for Outstanding Leaders in Medical Disciplines in Shanghai (grant no. 2017BR031).

\section{Availability of data and materials}

Not applicable.

\section{Authors' contributions}

QL and YW put forward the conception and design of the manuscript, and ZZZ and YW were major contributors in writing the manuscript. All authors read and approved the final manuscript.

\section{Ethics approval and consent to participate}

Not applicable.

\section{Patient consent for publication}

Not applicable.

\section{Competing interests}

The authors declare that they have no competing interests.

\section{References}

1. Dhabhar FS and McEwen BS: Acute stress enhances while chronic stress suppresses cell-mediated immunity in vivo: A potential role for leukocyte trafficking. Brain Behav Immun 11: 286-306, 1997.

2. Amin SN, El-Aidi AA, Ali MM, Attia YM and Rashed LA: Modification of hippocampal markers of synaptic plasticity by memantine in animal models of acute and repeated restraint stress: Implications for memory and behavior. Neuromolecular Med 17: 121-136, 2015.

3. Charmandari E, Tsigos $\mathrm{C}$ and Chrousos G: Endocrinology of the stress response. Annu Rev Physiol 67: 259-284, 2005.

4. Gunnar M and Quevedo K: The neurobiology of stress and development. Annu Rev Psychol 58: 145-173, 2007.

5. Krizanova O, Babula P and Pacak K: Stress, catecholaminergic system and cancer. Stress 19: 419-428, 2016.

6. Hering D, Lachowska K and Schlaich M: Role of the sympathetic nervous system in stress-mediated cardiovascular disease. Curr Hypertens Rep 17: 80, 2015.

7. Dhabhar FS, McEwen BS and Spencer RL: Stress response, adrenal steroid receptor levels and corticosteroid-binding globulin levels - a comparison between Sprague-Dawley, Fischer 344 and Lewis rats. Brain Res 616: 89-98, 1993.

8. Dhabhar FS, McEwen BS and Spencer RL: Adaptation to prolonged or repeated stress - comparison between rat strains showing intrinsic differences in reactivity to acute stress. Neuroendocrinology 65: 360-368, 1997.

9. Ambarish V, Chandrashekara S and Suresh KP: Moderate regular exercises reduce inflammatory response for physical stress. Indian J Physiol Pharmacol 56: 7-14, 2012.

10. Clague $J$ and Bernstein L: Physical activity and cancer. Curr Oncol Rep 14: 550-558, 2012.

11. Dhabhar FS: Effects of stress on immune function: The good, the bad, and the beautiful. Immunol Res 58: 193-210, 2014.

12. Lagraauw HM, Kuiper J and Bot I: Acute and chronic psychological stress as risk factors for cardiovascular disease: Insights gained from epidemiological, clinical and experimental studies. Brain Behav Immun 50: 18-30, 2015.

13. Muffly LS, Hlubocky FJ, Khan N, Wroblewski K, Breitenbach K, Gomez J, McNeer JL, Stock W and Daugherty CK: Psychological morbidities in adolescent and young adult blood cancer patients during curative-intent therapy and early survivorship. Cancer 122: 954-961, 2016.

14. Cohen L, Cole SW, Sood AK, Prinsloo S, Kirschbaum C, Arevalo JM, Jennings NB, Scott S, Vence L, Wei Q, et al: Depressive symptoms and cortisol rhythmicity predict survival in patients with renal cell carcinoma: Role of inflammatory signaling. PLoS One 7: e42324, 2012.

15. Shan T, Ma J, Ma Q, Guo K, Guo J, Li X, Li W, Liu J, Huang C, Wang F, et al: $\beta 2$-AR-HIF-1 $\alpha$ : A novel regulatory axis for stressinduced pancreatic tumor growth and angiogenesis. Curr Mol Med 13: 1023-1034, 2013.

16. Iwata M, Ota KT, Li XY, Sakaue F, Li N, Dutheil S, Banasr M, Duric V, Yamanashi T, Kaneko K, et al: Psychological stress activates the inflammasome via release of adenosine triphosphate and stimulation of the purinergic type $2 \times 7$ receptor. Biol Psychiatry 80: 12-22, 2016.

17. Agarwal SK and Marshall GD Jr: Stress effects on immunity and its application to clinical immunology. Clin Exp Allergy 31: 25-31, 2001

18. Yin X, Guven N and Dietis N: Stress-based animal models of depression: Do we actually know what we are doing? Brain Res 1652: 30-42, 2016.

19. Heinrichs SC and Koob GF: Application of experimental stressors in laboratory rodents. Curr Protoc Neurosci Chapter 8: Unit8.4, 2006.

20. Zorzet S, Perissin L, Rapozzi V and Giraldi T: Restraint stress reduces the antitumor efficacy of cyclophosphamide in tumorbearing mice. Brain Behav Immun 12: 23-33, 1998.

21. Nukina H, Sudo N, Aiba Y, Oyama N, Koga Y and Kubo C: Restraint stress elevates the plasma interleukin-6 levels in germ-free mice. J Neuroimmunol 115: 46-52, 2001. 
22. Willner P and Mitchell PJ; P W and PJ M: The validity of animal models of predisposition to depression. Behav Pharmacol 13: 169-188, 2002.

23. Glaser R and Kiecolt-Glaser JK: Stress-induced immune dysfunction: Implications for health. Nat Rev Immunol 5: 243-251, 2005.

24. Dhabhar FS, Saul AN, Daugherty C, Holmes TH, Bouley DM and Oberyszyn TM: Short-term stress enhances cellular immunity and increases early resistance to squamous cell carcinoma. Brain Behav Immun 24: 127-137, 2010

25. Eng JW, Kokolus KM, Reed CB, Hylander BL, Ma WW and Repasky EA: A nervous tumor microenvironment: The impact of adrenergic stress on cancer cells, immunosuppression, and immunotherapeutic response. Cancer Immunol Immunother 63: $1115-1128,2014$

26. Frick LR, Rapanelli M, Bussmann UA, Klecha AJ, Arcos ML, Genaro AM and Cremaschi GA: Involvement of thyroid hormones in the alterations of T-cell immunity and tumor progression induced by chronic stress. Biol Psychiatry 65: 935-942, 2009

27. Volpi S, Rabadan-Diehl C and Aguilera G: Vasopressinergic regulation of the hypothalamic pituitary adrenal axis and stress adaptation. Stress 7: 75-83, 2004.

28. MeltzerHY,Lowy MT and Koenig JI: The hypothalamic-pituitaryadrenal axis in depression. Adv Biochem Psychopharmacol 43: 165-182, 1987.

29. Chrousos GP: Ultradian, circadian, and stress-related hypothalamicpituitary-adrenal axis activity - a dynamic digital-to-analog modulation. Endocrinology 139: 437-440, 1998.

30. Sephton S and Spiegel D: Circadian disruption in cancer: A neuroendocrine-immune pathway from stress to disease? Brain Behav Immun 17: 321-328, 2003.

31. McEwen BS: Physiology and neurobiology of stress and adaptation: Central role of the brain. Physiol Rev 87: 873-904, 2007.

32. Moreno-Smith M, Lutgendorf SK and Sood AK: Impact of stress on cancer metastasis. Future Oncol 6: 1863-1881, 2010.

33. Gündisch S, Boeckeler E, Behrends U, Amtmann E, Ehrhardt H and Jeremias I: Glucocorticoids augment survival and proliferation of tumor cells. Anticancer Res 32: 4251-4261, 2012.

34. Wang HM, Liao ZX, Komaki R, Welsh JW, O'Reilly MS Chang JY, Zhuang Y, Levy LB, Lu C and Gomez DR: Improved survival outcomes with the incidental use of beta-blockers among patients with non-small-cell lung cancer treated with definitive radiation therapy. Ann Oncol 24: 1312-1319, 2013.

35. Wulsin AC, Wick-Carlson D, Packard BA, Morano R and Herman JP: Adolescent chronic stress causes hypothalamopituitary-adrenocortical hypo-responsiveness and depression-like behavior in adult female rats. Psychoneuroendocrinology 65 109-117, 2016

36. Bortolato B, Hyphantis TN, Valpione S, Perini G, Maes M, Morris G, Kubera M, Köhler CA, Fernandes BS, Stubbs B, et al: Depression in cancer: The many biobehavioral pathways driving tumor progression. Cancer Treat Rev 52: 58-70, 2017.

37. Zhao L, Xu J, Liang F, Li A, Zhang Y and Sun J: Effect of chronic psychological stress on liver metastasis of colon cancer in mice. PLoS One 10: e0139978, 2015.

38. Xie H, Li C, He Y, Griffin R, Ye Q and Li L: Chronic stress promotes oral cancer growth and angiogenesis with increased circulating catecholamine and glucocorticoid levels in a mouse model. Oral Oncol 51: 991-997, 2015.

39. Liu J, Deng GH, Zhang J, Wang Y, Xia XY, Luo XM, Deng YT, He SS, Mao YY, Peng XC, et al: The effect of chronic stress on anti-angiogenesis of sunitinib in colorectal cancer models Psychoneuroendocrinology 52: 130-142, 2015.

40. Elefteriou F: Chronic stress, sympathetic activation and skeletal metastasis of breast cancer cells. Bonekey Rep 4: 693, 2015.

41. Moreno-Smith M, Lu C, Shahzad MM, Pena GN, Allen JK, Stone RL, Mangala LS, Han HD, Kim HS, Farley D, et al: Dopamine blocks stress-mediated ovarian carcinoma growth. Clin Cancer Res 17: 3649-3659, 2011.

42. Moreno-Smith M, Lee SJ, Lu C, Nagaraja AS, He G, Rupaimoole R, Han HD, Jennings NB, Roh JW, Nishimura M, et al: Biologic effects of dopamine on tumor vasculature in ovarian carcinoma. Neoplasia 15: 502-510, 2013

43. Borcherding DC, Tong W, Hugo ER, Barnard DF, Fox S, LaSance K, Shaughnessy E and Ben-Jonathan N: Expression and therapeutic targeting of dopamine receptor-1 (D1R) in breast cancer. Oncogene 35: 3103-3113, 2016.

44. Peters MA, Walenkamp AM, Kema IP, Meijer C, de Vries EG and Oosting SF: Dopamine and serotonin regulate tumor behavior by affecting angiogenesis. Drug Resist Updat 17: 96-104, 2014.
45. Barbieri A, Palma G, Rosati A, Giudice A, Falco A, Petrillo A, Petrillo M, Bimonte S, Di Benedetto M, Esposito G, et al: Role of endothelial nitric oxide synthase (eNOS) in chronic stresspromoted tumour growth. J Cell Mol Med 16: 920-926, 2012.

46. Partecke LI, Speerforck S, Käding A, Seubert F, Kühn S, Lorenz E, Schwandke S, Sendler M, Kessler W, Trung DN, et al: Chronic stress increases experimental pancreatic cancer growth, reduces survival and can be antagonised by beta-adrenergic receptor blockade. Pancreatology 16: 423-433, 2016.

47. Feng Z, Liu L, Zhang C, Zheng T, Wang J, Lin M, Zhao Y, Wang X, Levine AJ and $\mathrm{Hu} \mathrm{W}$ : Chronic restraint stress attenuates p53 function and promotes tumorigenesis. Proc Natl Acad Sci USA 109: 7013-7018, 2012

48. Gao J, Gao G, Zhang Y and Wang F: Proteomic analysis of human epithelial ovarian cancer xenografts in immunodeficient mice exposed to chronic psychological stress. Sci China Life Sci 54: 112-120, 2011.

49. Turnbull AV and Rivier CL: Regulation of the hypothalamicpituitary-adrenal axis by cytokines: Actions and mechanisms of action. Physiol Rev 79: 1-71, 1999.

50. Schwab CL, Fan R, Zheng Q, Myers LP, Hebert P and Pruett SB: Modeling and predicting stress-induced immunosuppression in mice using blood parameters. Toxicol Sci 83: 101-113, 2005.

51. Dhabhar FS, Malarkey WB, Neri E and McEwen BS: Stress-induced redistribution of immune cells - from barracks to boulevards to battlefields: A tale of three hormones - Curt Richter Award winner. Psychoneuroendocrinology 37: 1345-1368, 2012.

52. Barbieri A, Bimonte S, Palma G, Luciano A, Rea D, Giudice A, Scognamiglio G, La Mantia E, Franco R, Perdonà S, et al: The stress hormone norepinephrine increases migration of prostate cancer cells in vitro and in vivo. Int J Oncol 47: 527-534, 2015.

53. Nilsson MB, Sun H, Diao L, Tong P, Liu D, Li L, Fan Y, Poteete A, Lim SO, Howells K, et al: Stress hormones promote EGFR inhibitor resistance in NSCLC: Implications for combinations with $\beta$-blockers. Sci Transl Med 9: 9, 2017.

54. Kim-Fuchs C, Le CP, Pimentel MA, Shackleford D, Ferrari D, Angst E, Hollande F and Sloan EK: Chronic stress accelerates pancreatic cancer growth and invasion: A critical role for betaadrenergic signaling in the pancreatic microenvironment. Brain Behav Immun 40: 40-47, 2014.

55. Nagaraja AS, Sadaoui NC, Dorniak PL, Lutgendorf SK and Sood AK: SnapShot: Stress and Disease. Cell Metab 23: 388-388.e1, 2016.

56. Dhabhar FS: Enhancing versus suppressive effects of stress on immune function: Implications for immunoprotection and immunopathology. Neuroimmunomodulation 16: 300-317, 2009.

57. Glaser R, MacCallum RC, Laskowski BF, Malarkey WB, Sheridan JF and Kiecolt-Glaser JK: Evidence for a shift in the Th-1 to Th-2 cytokine response associated with chronic stress and aging. J Gerontol A Biol Sci Med Sci 56: M477-M482, 2001

58. Ochoa CE, Mirabolfathinejad SG, Ruiz VA, Evans SE, Gagea M, Evans CM, Dickey BF and Moghaddam SJ: Interleukin 6, but not T helper 2 cytokines, promotes lung carcinogenesis. Cancer Prev Res (Phila) 4: 51-64, 2011

59. Divyashree S, Sarjan HN and Yajurvedi HN: Effects of long-term chronic stress on the lymphoid organs and blood 1. Can J Zool 94: 137-143, 2015.

60. Frick LR, Arcos ML, Rapanelli M, Zappia MP, Brocco M, Mongini C, Genaro AM and Cremaschi GA: Chronic restraint stress impairs T-cell immunity and promotes tumor progression in mice. Stress 12: 134-143, 2009.

61. Li H, Zhao J, Chen M, Tan Y, Yang X, Caudle Y and Yin D: Toll-like receptor 9 is required for chronic stress-induced immune suppression. Neuroimmunomodulation 21: 1-7, 2014.

62. Lakshmi Narendra B, Eshvendar Reddy K, Shantikumar S and Ramakrishna S: Immune system: a double-edged sword in cancer. Inflamm Res 62: 823-834, 2013.

63. Hunzeker JT, Elftman MD, Mellinger JC, Princiotta MF, Bonneau RH, Truckenmiller ME and Norbury CC: A marked reduction in priming of cytotoxic $\mathrm{CD} 8^{+} \mathrm{T}$ cells mediated by stress-induced glucocorticoids involves multiple deficiencies in cross-presentation by dendritic cells. J Immunol 186: 183-194, 2011.

64. Kour K and Bani S: Augmentation of immune response by chicoric acid through the modulation of CD28/CTLA-4 and Th1 pathway in chronically stressed mice. Neuropharmacology 60 : $852-860,2011$

65. Lutgendorf SK, Sood AK, Anderson B, McGinn S, Maiseri H, Dao M, Sorosky JI, De Geest K, Ritchie J and Lubaroff DM: Social support, psychological distress, and natural killer cell activity in ovarian cancer. J Clin Oncol 23: 7105-7113, 2005. 
66. Reiche EM, Nunes SO and Morimoto HK: Stress, depression, the immune system, and cancer. Lancet Oncol 5: 617-625, 2004.

67. Nakatani Y, Amano T and Takeda H: Corticosterone suppresses the proliferation of RAW264.7 macrophage cells via glucocorticoid, but not mineralocorticoid, receptor. Biol Pharm Bull 36 : 592-601, 2013.

68. Sloan EK, Priceman SJ, Cox BF, Yu S, Pimentel MA, Tangkanangnukul V, Arevalo JM, Morizono K, Karanikolas BD, $\mathrm{Wu} \mathrm{L}$, et al: The sympathetic nervous system induces a metastatic switch in primary breast cancer. Cancer Res 70: 7042-7052, 2010

69. Schmieder A, Michel J,Schönhaar K, Goerdt S and Schledzewski K Differentiation and gene expression profile of tumor-associated macrophages. Semin Cancer Biol 22: 289-297, 2012.

70. Armaiz-Pena GN, Gonzalez-Villasana V, Nagaraja AS, Rodriguez-Aguayo C, Sadaoui NC, Stone RL, Matsuo K, Dalton HJ, Previs RA, Jennings NB, et al: Adrenergic regulation of monocyte chemotactic protein 1 leads to enhanced macrophage recruitment and ovarian carcinoma growth. Oncotarget 6 : 4266-4273, 2015.

71. Roberts DD, Miller TW, Rogers NM, Yao M and Isenberg JS: The matricellular protein thrombospondin-1 globally regulates cardiovascular function and responses to stress via CD47. Matrix Biol 31: 162-169, 2012.

72. Barkal AA, Weiskopf K, Kao KS, Gordon SR, Rosental B, Yiu YY, George BM, Markovic M, Ring NG, Tsai JM, et al: Engagement of MHC class I by the inhibitory receptor LILRB1 suppresses macrophages and is a target of cancer immunotherapy. Nat Immunol 19: 76-84, 2018.

73. Hanke N, Alizadeh D, Katsanis E and Larmonier N: Dendritic cell tumor killing activity and its potential applications in cancer immunotherapy. Crit Rev Immunol 33: 1-21, 2013.

74. Wu W, Sun M, Zhang HP, Chen T, Wu R, Liu C, Yang G, Geng XR, Feng BS, Liu Z, et al: Prolactin mediates psychological stressinduced dysfunction of regulatory $\mathrm{T}$ cells to facilitate intestinal inflammation. Gut 63: 1883-1892, 2014

75. Dhabhar FS, Satoskar AR, Bluethmann H, David JR and McEwen BS: Stress-induced enhancement of skin immune function: A role for gamma interferon. Proc Natl Acad Sci USA 97: 2846-2851, 2000

76. Dhabhar FS and Viswanathan K: Short-term stress experienced at time of immunization induces a long-lasting increase in immunologic memory. Am J Physiol Regul Integr Comp Physiol 289: R738-R744, 2005.

77. Levi B, Benish M, Goldfarb Y, Sorski L, Melamed R, Rosenne E and Ben-Eliyahu S: Continuous stress disrupts immunostimulatory effects of IL-12. Brain Behav Immun 25: 727-735, 2011.

78. Lopes RP, Grassi-Oliveira R, de Almeida LR, Stein LM, Luz C, Teixeira AL and Bauer ME: Neuroimmunoendocrine interactions in patients with recurrent major depression, increased early life stress and long-standing posttraumatic stress disorder symptoms. Neuroimmunomodulation 19: 33-42, 2012.

79. Dhabhar FS and McEwen BS: Stress-induced enhancement of antigen-specific cell-mediated immunity. J Immunol 156 2608-2615, 1996.

80. Stacker SA, Williams SP, Karnezis T, Shayan R, Fox SB and Achen MG: Lymphangiogenesis and lymphatic vessel remodelling in cancer. Nat Rev Cancer 14: 159-172, 2014.

81. Le CP, Nowell CJ, Kim-Fuchs C, Botteri E, Hiller JG, Ismail H, Pimentel MA, Chai MG, Karnezis T, Rotmensz N, et al: Chronic stress in mice remodels lymph vasculature to promote tumour cell dissemination. Nat Commun 7: 10634, 2016.

82. Boleij A and Tjalsma H: Gut bacteria in health and disease: A survey on the interface between intestinal microbiology and colorectal cancer. Biol Rev Camb Philos Soc 87: 701-730, 2012.

83. O'Toole PW and Jeffery IB; PW OT and IB J: Gut microbiota and aging. Science 350: 1214-1215, 2015.

84. Rook GAW, Raison CL and Lowry CA: Microbiota, immunoregulatory old friends and psychiatric disorders. Adv Exp Med Biol 817: 319-356, 2014

85. Penders J, Gerhold K, Stobberingh EE, Thijs C, Zimmermann K, Lau S and Hamelmann E: Establishment of the intestinal microbiota and its role for atopic dermatitis in early childhood. J Allergy Clin Immunol 132: 601-607.e8, 2013.

86. Gagnière J, Raisch J, Veziant J, Barnich N, Bonnet R, Buc E, Bringer MA, Pezet D and Bonnet M: Gut microbiota imbalance and colorectal cancer. World J Gastroenterol 22: 501-518, 2016.

87. Paul B, Barnes S, Demark-Wahnefried W, Morrow C, Salvador C, Skibola $\mathrm{C}$ and Tollefsbol TO: Influences of diet and the gut microbiome on epigenetic modulation in cancer and other diseases. Clin Epigenetics 7: 112, 2015.
88. Berni Canani R, Di Costanzo M and Leone L: The epigenetic effects of butyrate: Potential therapeutic implications for clinical practice. Clin Epigenetics 4: 4, 2012.

89. Yamamoto ML, Maier I, Dang AT, Berry D, Liu J, Ruegger PM, Yang JI, Soto PA, Presley LL, Reliene R, et al: Intestinal bacteria modify lymphoma incidence and latency by affecting systemic inflammatory state, oxidative stress, and leukocyte genotoxicity. Cancer Res 73: 4222-4232, 2013.

90. Maslowski KM, Vieira AT, Ng A, Kranich J, Sierro F, Yu D, Schilter HC, Rolph MS, Mackay F, Artis D, et al: Regulation of inflammatory responses by gut microbiota and chemoattractant receptor GPR43. Nature 461: 1282-1286, 2009

91. Garrett WS: Cancer and the microbiota. Science 348: 80-86, 2015

92. Iida N, Dzutsev A, Stewart CA, Smith L, Bouladoux N, Weingarten RA, Molina DA, Salcedo R, Back T, Cramer S, et al: Commensal bacteria control cancer response to therapy by modulating the tumor microenvironment. Science 342: 967-970, 2013.

93. Vétizou M, Pitt JM, Daillère R, Lepage $P$, Waldschmitt $N$, Flament C, Rusakiewicz S, Routy B, Roberti MP, Duong CP, et al: Anticancer immunotherapy by CTLA-4 blockade relies on the gut microbiota. Science 350: 1079-1084, 2015.

94. Sudo N, Chida Y, Aiba Y, Sonoda J, Oyama N, Yu XN, Kubo C and Koga Y: Postnatal microbial colonization programs the hypothalamic-pituitary-adrenal system for stress response in mice. J Physiol 558: 263-275, 2004

95. Luna RA and Foster JA: Gut brain axis: Diet microbiota interactions and implications for modulation of anxiety and depression. Curr Opin Biotechnol 32: 35-41, 2015.

96. Naseribafrouei A, Hestad K, Avershina E, Sekelja M, Linløkken A, Wilson R and Rudi K: Correlation between the human fecal microbiota and depression. Neurogastroenterol Motil 26: 1155-1162, 2014.

97. Crumeyrolle-Arias M, Jaglin M, Bruneau A, Vancassel S, Cardona A, Daugé V, Naudon L and Rabot S: Absence of the gut microbiota enhances anxiety-like behavior and neuroendocrine response to acute stress in rats. Psychoneuroendocrinology 42: 207-217, 2014.

98. Liang S, Wang T, Hu X, Luo J, Li W, Wu X, Duan Y and Jin F: Administration of Lactobacillus helveticus NS8 improves behavioral, cognitive, and biochemical aberrations caused by chronic restraint stress. Neuroscience 310: 561-577, 2015.

99. Xu D, Gao J, Gillilland M III, Wu X, Song I, Kao JY and Owyang C: Rifaximin alters intestinal bacteria and prevents stress-induced gut inflammation and visceral hyperalgesia in rats. Gastroenterology 146: 484-96.e4, 2014.

100. Ait-Belgnaoui A, Durand H, Cartier C, Chaumaz G, Eutamene H, Ferrier L, Houdeau E, Fioramonti J, Bueno L and Theodorou V: Prevention of gut leakiness by a probiotic treatment leads to attenuated HPA response to an acute psychological stress in rats. Psychoneuroendocrinology 37: 1885-1895, 2012

101. Seidel DV, Azcárate-Peril MA, Chapkin RS and Turner ND: Shaping functional gut microbiota using dietary bioactives to reduce colon cancer risk. Semin Cancer Biol 46: 191-204, 2017.

102. Gopalakrishnan V, Spencer CN, Nezi L, Reuben A, Andrews MC, Karpinets TV, Prieto PA, Vicente D, Hoffman K, Wei SC, et al: Gut microbiome modulates response to anti-PD-1 immunotherapy in melanoma patients. Science 359: 97-103, 2018.

103. Balkwill FR and Mantovani A: Cancer-related inflammation: Common themes and therapeutic opportunities. Semin Cancer Biol 22: 33-40, 2012

104. Hanahan D and Weinberg RA: Hallmarks of cancer: The next generation. Cell 144: 646-674, 2011.

105. Elinav E, Nowarski R, Thaiss CA, Hu B, Jin C and Flavell RA: Inflammation-induced cancer: Crosstalk between tumours, immune cells and microorganisms. Nat Rev Cancer 13: 759-771, 2013.

106. Aggarwal BB, Vijayalekshmi RV and Sung B: Targeting inflammatory pathways for prevention and therapy of cancer: short-term friend, long-term foe. Clin Cancer Res 15: 425-430, 2009.

107. Thaker PH, Han LY, Kamat AA, Arevalo JM, Takahashi R, Lu C, Jennings NB, Armaiz-Pena G, Bankson JA, Ravoori M, et al: Chronic stress promotes tumor growth and angiogenesis in a mouse model of ovarian carcinoma. Nat Med 12: 939-944, 2006.

108. Armaiz-Pena GN, Cole SW, Lutgendorf SK and Sood AK Neuroendocrine influences on cancer progression. Brain Behay Immun 30 (Suppl): S19-S25, 2013.

109. Kyrou I, Tsigos C, Seedorf K and Ferré P: Stress hormones: Physiological stress and regulation of metabolism. Curr Opin Pharmacol 9: 787-793,2009. 
110. Lu XT, Liu YF, Zhao L, Li WJ, Yang RX, Yan FF, Zhao YX and Jiang F: Chronic psychological stress induces vascular inflammation in rabbits. Stress 16: 87-98, 2013.

111. Ahmad SF, Zoheir KM, Ansari MA, Korashy HM, Bakheet SA, Ashour AE and Attia SM: Stimulation of the histamine 4 receptor with 4-methylhistamine modulates the effects of chronic stress on the Th1/Th2 cytokine balance. Immunobiology 220: 341-349, 2015.

112. Powell ND, Tarr AJ and Sheridan JF: Psychosocial stress and inflammation in cancer. Brain Behav Immun 30 (Suppl) S41-S47, 2013.

113.Zitvogel L, Kepp O, Galluzzi L and Kroemer G: Inflammasomes in carcinogenesis and anticancer immune responses. Nat Immunol 13: 343-351, 2012.

114. Müzes G and Sipos F: Inflammasome, inflammation and cancer: An interrelated pathobiological triad. Curr Drug Targets 16 249-257, 2015

115. Dunn JH, Ellis LZ and Fujita M: Inflammasomes as molecular mediators of inflammation and cancer: Potential role in melanoma Cancer Lett 314: 24-33, 2012.

116. Shahzad MM, Arevalo JM, Armaiz-Pena GN, Lu C, Stone RL, Moreno-Smith M, Nishimura M, Lee JW, Jennings NB, Bottsford-Miller J, et al: Stress effects on FosB- and interleukin-8 (IL8)-driven ovarian cancer growth and metastasis. J Biol Chem 285: 35462-35470, 2010.

117. Cosci F, Fava GA and Sonino N: Mood and anxiety disorders as early manifestations of medical illness: A systematic review. Psychother Psychosom 84: 22-29, 2015.

118. Casorelli I, Bossa C and Bignami M: DNA damage and repair in human cancer: Molecular mechanisms and contribution to therapy-related leukemias. Int J Environ Res Public Health 9 : 2636-2657, 2012.

119. Higgins CF: Multiple molecular mechanisms for multidrug resistance transporters. Nature 446: 749-757, 2007.

120. Abraham J, Salama NN and Azab AK: The role of P-glycoprotein in drug resistance in multiple myeloma. Leuk Lymphoma 56: $26-33,2015$

121. Su F, Ouyang N, Zhu P, Ouyang N, Jia W, Gong C, Ma X, Xu H and Song E: Psychological stress induces chemoresistance in breast cancer by upregulating mdr1. Biochem Biophys Res Commun 329: 888-897, 2005.

122.Reeder A, Attar M, Nazario L, Bathula C, Zhang A, Hochbaum D, Roy E, Cooper KL, Oesterreich S, Davidson NE, et al: Stress hormones reduce the efficacy of paclitaxel in triple negative breast cancer through induction of DNA damage. Br J Cancer 112: 1461-1470, 2015.

123. Yao H, Duan Z, Wang M, Awonuga AO, Rappolee D and Xie Y: Adrenaline induces chemoresistance in HT-29 colon adenocarcinoma cells. Cancer Genet Cytogenet 190: 81-87, 2009.
124. Pu J, Bai D, Yang X, Lu X, Xu L and Lu J: Adrenaline promotes cell proliferation and increases chemoresistance in colon cancer HT29 cells through induction of miR-155. Biochem Biophys Res Commun 428: 210-215, 2012.

125. Kong W, He L, Coppola M, Guo J, Esposito NN, Coppola D and Cheng JQ: MicroRNA-155 regulates cell survival, growth, and chemosensitivity by targeting FOXO3a in breast cancer. J Biol Chem 285: 17869-17879, 2010

126. Hassan S, Karpova Y, Baiz D, Yancey D, Pullikuth A, Flores A, Register T, Cline JM, D'Agostino R Jr, Danial N, et al: Behavioral stress accelerates prostate cancer development in mice. J Clin Invest 123: 874-886, 2013.

127. Sun X, Bao J, Nelson KC, Li KC, Kulik G and Zhou X: Systems modeling of anti-apoptotic pathways in prostate cancer: Psychological stress triggers a synergism pattern switch in drug combination therapy. PLOS Comput Biol 9: e1003358, 2013.

128. Geller LT, Barzily-Rokni M, Danino T, Jonas OH, Shental N, Nejman D, Gavert N,Zwang Y, CooperZA, Shee K, et al: Potential role of intratumor bacteria in mediating tumor resistance to the chemotherapeutic drug gemcitabine. Science 357: 1156-1160, 2017.

129. van Bodegom M, Homberg JR and Henckens MJAG: Modulation of the hypothalamic-pituitary-adrenal axis by early life stress exposure. Front Cell Neurosci 11: 87, 2017.

130. Antoni MH: Psychosocial intervention effects on adaptation, disease course and biobehavioral processes in cancer. Brain Behav Immun 30 (Suppl): S88-S98, 2013.

131. Saxton JM, Scott EJ, Daley AJ, Woodroofe M, Mutrie N, Crank H, Powers HJ and Coleman RE: Effects of an exercise and hypocaloric healthy eating intervention on indices of psychological health status, hypothalamic-pituitary-adrenal axis regulation and immune function after early-stage breast cancer: A randomised controlled trial. Breast Cancer Res 16: R39, 2014

132. Chida Y, Hamer M, Wardle J and Steptoe A: Do stress-related psychosocial factors contribute to cancer incidence and survival? Nat Clin Pract Oncol 5: 466-475, 2008.

133. Dieli-Conwright CM and Orozco BZ: Exercise after breast cancer treatment: Current perspectives. Breast Cancer (Dove Med Press) 7: 353-362, 2015

134. Nota JA and Coles ME: Shorter sleep duration and longer sleep onset latency are related to difficulty disengaging attention from negative emotional images in individuals with elevated transdiagnostic repetitive negative thinking. J Behav Ther Exp Psychiatry 58: 114-122, 2018.

135. Guzman-Marin R and Avidan AY: Sleep disorders in patients with cancer. J Community Support Oncol 13: 148-155, 2015. 